\title{
In vitro Antioxidant activity of ethanol and aqueous extracts of Eugenia operculata Roxb.
}

\author{
Yumnam Romila Devi*, Pranab Behari Mazumder \\ Department of Biotechnology, Assam University, Silcher, India-788011
}

\begin{abstract}
Eugenia operculata Roxb. also known as Cleistocalyx operculatus Roxb., or Syzygium nervosum belongs to the myrtaceae family is a well known perennial tree, commonly known as tom heinou in Manipur, India. The purpose of this study was to elucidate the antioxidant capacities of E.operculata. The ethanol and aqueous extracts were used in the present study. The extracts were screened for the presence of phytochemical constituents. Antioxidant properties were determined by using 1,1-diphenyl-2-picrylhydrazyl (DPPH) assay and reducing power method.IC $C_{50}$ values of ethanol and aqueous extracts were found to be $52.96 \pm 0.94$ and $41.73 \pm 0.4$ for DPPH assay. Reducing assay reveals dose dependent reducing power. The extract showed potent antioxidant activity when compared with standard ascorbic acid and gallic acid. Total phenolic content for ethanol and aqueous extracts were found to be 58.6 and $88.1 \mathrm{mg} / \mathrm{gm}$ GAE. The ethanol and aqueous extracts of E.operculta posses significant antioxidant activity.

Keywords: Antioxidant, DPPH, Eugenia operculata; Manipur; Phytochemicals
\end{abstract}

\section{Introduction:}

A free-radical is simply defined as any species capable of independent existence that contains one or more unpaired electrons, an unpaired electrons being one that is alone in an orbital. They are fundamental to any biochemical process and represent an essential part of aerobic life and our metabolism. They are continuously produced by the body's normal used of oxygen such as respiration and some cell mediated immune functions. Also free radicals are generated through certain environmental pollutants.

However continuous interaction of the animal physiological systems with these free radicals generated either indigenously or inhaled/ingested from exogenous sources therefore, lead to excess load of free radicals and cause cumulative damage of protein, lipid, DNA, carbohydrates and membrane, resulting in so- called oxidative stress ${ }^{1}$. Therefore, living creatures have evolved a highly complicated defense system with antioxidants composed of enzymes and vitamins against oxidative stress in the course of their evolution. These defense systems are mainly classified as (i) suppression of generation of ROS, (ii) scavenging of ROS, (iii) clearance, repairing and reconstitution of damage and (iv) induction of antioxidant proteins and enzymes ${ }^{2}$. However, amounts of these protective devices present under normal physiological conditions are sufficient only to cope with the normal threshold of physiological rate of free-radical generation. Therefore, any additional burden of free radicals, either from an indigenous or exogenous source on the animal (human) physiological system can tip free radical (prooxidant) and anti-free radical (antioxidant) balance leading to oxidative stress ${ }^{3}$. At present many synthetic antioxidants are produced such as butylated hydroxyanisole (BHA), butylated hydroxyltoluene (BHT), and ter-butyl hydro quinone (TBHQ) still more than $80 \%$ people relies on medicinal plants or natural products due to the adverse side effects. Therefore it is prudent to look for options in herbal medicines.

Eugenia operculata Roxb. is a well known perennial tree, widely distributed and propagated at sub Himalayan tract, Bihar, Orissa. And it is found growing in scatter locations in some places of Manipur. The leaves and buds of Eugenia operculata Roxb. have been used as an ingredient in various beverage, common tea for gastrointestinal disorder and as antiseptic for dermatophytic disorders for many years ${ }^{4}$. Previous reports revealed that the $\mathrm{C}$. operculatus buds had various biological activities in vitro and in vivo such as anticancer, antitumor, antihyperglycemic and cardio tonic action ${ }^{5}$. So, for a healthy biological system, the balance between antioxidation and oxidation is believed to be a critical concept as imbalance leads to oxidative stress that is being suggested as the root cause of many deadly diseases. The present work has been designed to evaluate the phytochemical constituents, antioxidant potential and quantitative total phenolic contents of aqueous and ethanol leave extracts of E.operculata Roxb.

\section{Materials And Methods:}

\section{Collection and authentication of plant:}

Fresh leaves of Eugenia operculata were collected in the month of february from Lilong chajing, Manipur,India. The plant was authenticated as Eugenia operculata Roxb by Botanical Survey of India, Shillong. 


\section{Preparation of extracts:}

The leaves of the plants are properly washed under tap water and then rinsed with distilled water. The rinsed leaves were air dried in the shade and coarsely powdered in a grinder. The aqueous and ethanol extracts were prepared by extracting 100 grams of air dried powder in a soxhlet apparatus. Subsequently, the extracts were filtered, concentrated and dried using rotary evaporator under reduced pressure and the residue was stored in desiccators till subsequent use.

\section{Preliminary Phytochemical Screening:}

The ethanol and aqueous extract of Eugenia operculata were screened for phytochemical constituents using standard procedures of analysis ${ }^{6,7}$.

3.1. Detection of Alkaloid: Extracts were dissolved individually in dilute Hydrochloric acid and filtered. The filtrates were used.

a. Mayer's Test: Filtrates were treated with Mayer's reagent (Potassium Mercuric Iodide). Formation of a yellow coloured precipitate indicates the presence of alkaloids.

b. Wagner's Test: Filtrates were treated with Wagner's reagent (Iodine in Potassium Iodide). Formation of brown/reddish precipitate indicates the presence of alkaloids.

c. Hager's Test: Filtrates were treated with Hager's reagent (saturated picric acid solution). Presence of alkaloids was confirmed by the formation of yellow colored precipitate.

3.2. Detection of Carbohydrates: Extracts were dissolved individually in $5 \mathrm{ml}$ distilled waterand filtered. The filtrates were used to test for thepresence of carbohydrates.

a) Molisch's Test: Filtrates were treated with 2 drops of alcoholic $\alpha$-naphthol solution in a test tube and concentrated $\mathrm{H}_{2} \mathrm{SO}_{4}$ was added. Formation of the violet ring at the junction indicates the presence of Carbohydrates.

b) Benedict'Test: Filtrates were treated with Benedict's reagent and heated gently. Orange red precipitate indicates the presence of reducing sugars.

c) Fehling's Test: Filtrates were hydrolyzed with dilute $\mathrm{HCl}$, neutralized with alkali and heated with Fehling's A $\&$ B solutions. Formation of red precipitate indicates the presence of reducing sugars.

3.3. Detection of resins:

Acetone $\mathrm{H}_{2} \mathrm{O}$ tests: Extracts were treated with acetone. Small amount of water was added and shaken. Appearance of turbidity indicates the presence of resins.

\subsection{Detection of Flavonoids:}

a) Alkaline Reagent Test: Extracts were treated with 4-5 drops of sodium hydroxide solution. Formation of intense yellow colour, which becomes colourless on addition of dilute acid, indicates the presence of flavonoids.

b) Lead acetate Test: Extracts were treated with 4-5 drops of lead acetate solution. Formation of yellow colour precipitate indicates the presence of flavonoids.

c) Shinoda Test: To the alcoholic solution of extracts, a few fragments of magnesium ribbon and concentrated $\mathrm{HCl}$ was added. Appearance of magenta colour after few minutes indicates presence of flavonoids.

d) Zinc hydrochloric acid reduction Test: To the alcoholic solution of extracts, a pinch of Zinc dust and concentrated $\mathrm{HCl}$ was added. Appearance of magenta colour after few minutes indicates presence of flavonoids.

\subsection{Detection of Terpenoids:}

Salkowski test: To $0.5 \mathrm{~g}$ each of the extract was added $2 \mathrm{ml}$ of chloroform. Concentrated $\mathrm{H}_{2} \mathrm{SO}_{4}(3 \mathrm{ml})$ was carefully added to form a layer. A reddish brown colouration of the interface indicates the presence of terpenoids

\subsection{Detection of Anthraquinones:}

$0.5 \mathrm{~g}$ of the extract was boiled with $10 \mathrm{ml}$ of $\mathrm{H}_{2} \mathrm{SO}_{4}$ ) and filtered while hot. The filtrate was shaken with $5 \mathrm{ml}$ of chloroform. The chloroform layer was pipette into another test tube and $1 \mathrm{ml}$ of dilute ammonia was added. The resulting solution was observed for colour changes.

\subsection{Detection of Diterpenes:}

Copper acetate test: Extracts were dissolved in water and treated with 3-4 drops of copper acetate solution. Formation of emerald green colour indicates the presence of diterpenes.

3.8. Detection of Glycosides: Extracts were hydrolysed with dilute $\mathrm{HCl}$, and then subjected to test for glycosides.

a) Borntrager's Test: Extracts were treated with Ferric Chloride solution and immersed in boiling water for about 5 minutes. The mixture was cooled and extracted with equal volumes of benzene. The benzene layer was 
separated and treated with ammonia solution. Formation of rose pink colour in the ammonical layer indicates the presence of anthranol glycosides.

b) Legal's Test: Extracts were treated with sodium nitropruside in pyridine and sodium hydroxide. Formation of pink to blood red colour indicates the presence of cardiac glycosides.

3.9. Detection of Phenols:

Ferric Chloride Test: Extracts were treated with 3-4 drops of ferric chloride solution. Formation of bluish black colour indicates the presence of phenols.

3.10. Detection of Tannins:

Gelatin Test: To the extract, $1 \%$ gelatin solution containing sodium chloride was added. Formation of white precipitate indicates the presence of tannins.

3.11. Detection of Proteins and Aminoacids:

a) Xanthoproteic Test: The extracts were treated with 4-5 drops of concentrated Nitric acid. Formation of yellow colour indicates the presence of proteins.

b) Ninhydrin Test: To the extract, $0.25 \% \mathrm{w} / \mathrm{v}$ ninhydrin reagent was added and boiled for few minutes. Formation of blue colour indicates the presence of amino acid.

3.12. Detection of Cardiac Glycosides: Killer Kilani Test: To $0.5 \mathrm{~g}$ of extract diluted to $5 \mathrm{ml}$ in water was added $2 \mathrm{ml}$ of glacial acetic acid containing one drop of ferric chloride solution. This was underlayed with $1 \mathrm{ml}$ of concentrated $\mathrm{H}_{2} \mathrm{SO}_{4}$. A brown ring at the interface indicated the presence of a deoxysugar characteristic of cardenolides. A violet ring may appear below the brown ring, while in the acetic acid layer a greenish ring may form just above the brown ring and gradually spread throughout this layer.

4. DPPH free radical scavenging activity ${ }^{8}$ :

DPPH free radical scavenging assay was measured using DPPH free radical test, by employing the method of Wong et al. The different concentrations of each of the extracts were prepared in methanol and were added to $3 \mathrm{ml}$ of $0.1 \mathrm{mM}$ methanolic solution of DPPH. The tubes were shaken vigorously and allowed to stand for $30 \mathrm{~min}$ at room temperature in the dark. Changes in absorbance of samples were measured at $517 \mathrm{~nm}$. A control reading was obtained using methanol instead of the extract. Ascorbic acid served as the standard. Free radical scavenging activity was expressed as inhibition percentage and was calculated using the following formula,

Where,

$$
\% \text { Inhibition }=\left(\mathrm{A}_{0}-\mathrm{A}_{1}\right) / \mathrm{A}_{0} \mathrm{X} 100
$$

$\mathrm{A}_{0}$ is the absorbance of the control

$\mathrm{A}_{1}$ is the absorbance of test samples.

All the tests were performed in triplicates and the results are reported as IC50, which is the amount of antioxidant necessary to decrease the initial DPPH• concentration by $50 \%$.

5. Total phenolic analysis ${ }^{9}$ :

Total phenolic content of E.operculata extracts was measured by employing athe method described by Skerget et al.,2005 involving Foin-Ciocalteu reagent as an oxidizing agent and gallic acid as a standard. To $0.5 \mathrm{ml}$ of extract solution $(2 \mathrm{mg} / \mathrm{ml})$ in water, $2.5 \mathrm{ml}$ of Fiolin-Ciocalteu reagent (diluted 10 times with water) and $2.0 \mathrm{ml}$ of sodium carbonate $(7.5 \% \mathrm{w} / \mathrm{v})$ solution were added. After 20 minutes incubation at room temperature the absorbance was measured at 760nm using a UV-visible spectrophotometer. Total phenolic were quantified by calibration curve obtained from measuring the known concentration of gallic acid $(0-100 \mu \mathrm{g} / \mathrm{ml})$. The phenolic contents of the sample were expressed as gm of GAE (gallic acid equivalent)/100gm of the dried extract.

6. Reducing power assay:

A spectrophoptometric method ${ }^{\mathbf{1 0}}$ was used for the measurement of reducing power. For this $2.5 \mathrm{ml}$ of each of the extracts was mixed with $2.5 \mathrm{ml}$ phosphate buffer $(0.2 \mathrm{M} \mathrm{pH} 6.6)$ and $2.5 \mathrm{ml}$ of $1 \%$ potassium ferricyanide $(10 \mathrm{mg} / \mathrm{ml})$. The mixture was incubated at $50^{\circ} \mathrm{C}$ for $20 \mathrm{~min}$, then rapidly cooled, mixed with $2.5 \mathrm{ml}$ of $10 \%$ trichloroacetic acid and centrifuged at $6500 \mathrm{rpm}$ for $10 \mathrm{~min}$. An aliquot $(2.5 \mathrm{ml})$ of the supernatant was diluted with distilled water $(2.5 \mathrm{ml})$ and then ferric chloride $(0.5 \mathrm{ml}, 0.1 \%)$ was added and allowed to stand for $10 \mathrm{~min}$. The absorbance was read spectrophotometrically at 700nm. Ascorbic acid was used as standard for construction of the calibration curve and the reducing power was reported as ascorbic equivalent per 100gm of dry sample.

\section{Result And Discussion:}

1. Preliminary phytochemical screening of ethanol and aqueous extract of E.operculata showed many types of phytochemical constituents mainly flavonoids, phenols, carbohydrates, tannins and some resins, whereas alkaloids, glycosides, lignins and fixed oils were almost absent, Table 1. 
In vitro Antioxidant activity of ethanol and aqueous extracts of Eugenia operculata Roxb.

\begin{tabular}{|l|l|l|l|l|}
\hline S1/NO & Constituents & Test & \multicolumn{3}{l|}{ E.operculata } \\
\cline { 3 - 5 } & & & E.o-ethanol & $\begin{array}{l}\text { E.o- } \\
\text { Aqueous }\end{array}$ \\
\hline 1 & Alkaloids & $\begin{array}{l}\text { a.Meyer's test } \\
\text { b.Wagner's test } \\
\text { c.Hager's test }\end{array}$ & - & - \\
& & $\begin{array}{l}\text { a.Molisch's test } \\
\text { b.Benedict's test } \\
\text { c.Fehling's test }\end{array}$ & - & - \\
\hline 2 & Carbohydrates & Acetone H2O test & + & + \\
& & $\begin{array}{l}\text { a.Alkaline reagent test } \\
\text { b.Lead acetate test } \\
\text { c.ZincHCl reduction test } \\
\text { d.Shinoda test }\end{array}$ & + & + \\
\hline 3 & Resins & Salkowski's test & + & + \\
\hline 4 & Flavonoids & + & + \\
& & & + & + \\
\hline 5 & Terpenoids & Copper acetate test & + & + \\
\hline 6 & Anthraquinones & $\begin{array}{l}\text { a.ModifiedBorntrager's test } \\
\text { b.Legal's test }\end{array}$ & - & + \\
\hline 7 & Diterpenes & Ferric chloride test & - & - \\
\hline 8 & Glycosides & Gelatin test & - & - \\
\hline 9 & Phenols & $\begin{array}{l}\text { a.Xanthoproteic test } \\
\text { b.Ninhydrin test }\end{array}$ & - \\
\hline 10 & Tannins & Killer Kilani test & + & - \\
\hline 11 & Proteins and amino & - & + \\
\hline 12 & acids & Cardiac glycosides & - & + \\
\hline
\end{tabular}

Table 1. Preliminary phytochemical test

\section{Antioxidant activity of E.o extract}

The antioxidant activity of the extracts was determined using a DPPH scavenging assay. The DPPH assay is often used to evaluate the ability of antioxidants to scavenge free radicals which are known to be a major factor in biological damages caused by oxidative stress. This assay is known to give reliable information concerning the antioxidant ability of the tested compounds ${ }^{11}$. The principle of the assay is based on the color change of the DPPH solution from purple to yellow as the radical is quenched by the antioxidant ${ }^{12}$.resulting in a decrease in absorbance at $517 \mathrm{~nm}$. The addition of the extracts of E.operculata to the DPPH solution caused a rapid decrease in the optical density at $517 \mathrm{~nm}$ indicating the good scavenging activity of the extract. The extract showed substantial antioxidant activity in a dose dependent manner similar to that of ascorbic acid which was used as a control standard antioxidant. Fig1(A,B,C) illustrated the linear regression correlation of \%inhibition and concentration of the sample, showing positive relation with correlation coefficient $\left(R^{2}\right) 0.967,0.982,0.985$ bearing IC50 values $26.28 \pm 1.37 \mu \mathrm{g} / \mathrm{ml}, 52.96 \pm 0.94 \mu \mathrm{g} / \mathrm{ml}, 41.73 \pm 0.4 \mu \mathrm{g} / \mathrm{ml}$ for ascorbic acid, ethanol and aqueous respectively. Fig 1-C illustrated decreases in the concentration of DPPH radical due to the scavenging activity with increases in $\%$ inhibition.

Reducing power is associated with antioxidant activity and may serve as a significant reflection of the antioxidant activity ${ }^{13}$.It is a measure of reductive ability of antioxidants and it is evaluated by the transformation of $\mathrm{Fe}^{3+}$ to $\mathrm{Fe}^{2+}$ in the presence of extracts. In this assay, the yellow color of the test solution changes to various shades of green and blue depending on the reducing power of each compound. Fig2 A shows the reducing power of standard gallic acid, ethanol and aqueous extracts of E.operculata at different concentrations and it reveals that the reducing power of all the test increased with increase concentration.

Phenolics present in leaves have received considerable attention because of their potential antioxidant activities ${ }^{14}$. The total phenolic content of ethanol and aqueous extract of E.operculata were found to be 58.6 and $88.1 \mathrm{mg} / \mathrm{gm}$ GAE.

\section{Conclusion:}

Nowadays natural antioxidants have become a major area of interest in scientific research as Reactive Oxygen Species (ROS) are associated with the pathogenesis of various diseases and antioxidant acts by neutralizing the free radicals interactively and synergistically. The results obtained in the present study indicate that E.operculata leaves extract exhibit potent free radical scavenging and antioxidant activity in addition with concentration dependent reducing ability. The overall antioxidant activity might be attributed to its polyphenolic content and other phytochemical constituents. The finding of the present study suggest that E.operculata leaves could be a potential source of natural antioxidant that could have a great importance as therapeutic agents in preventing the progress of various oxidative stress. 
In vitro Antioxidant activity of ethanol and aqueous extracts of Eugenia operculata Roxb.
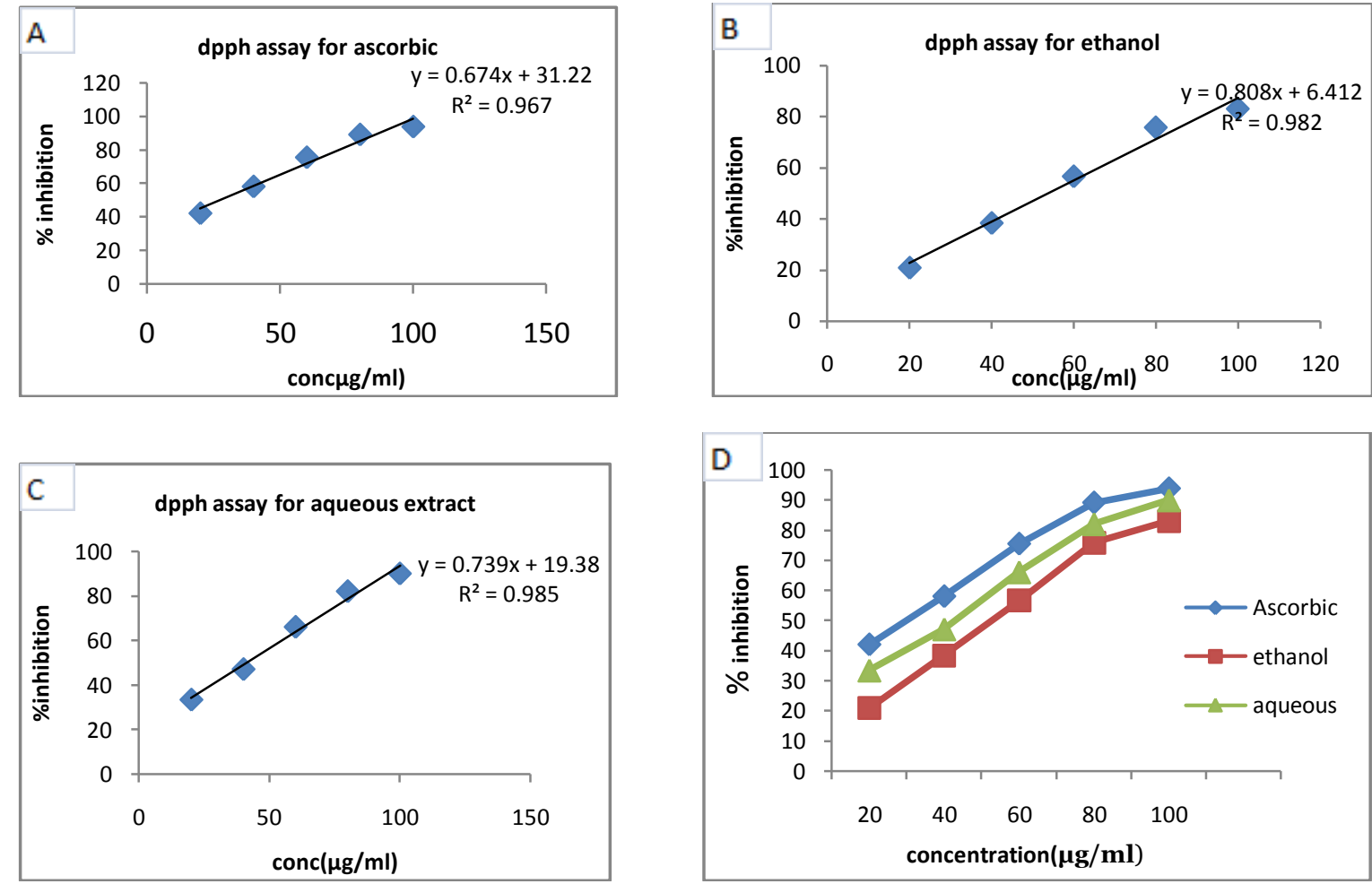

Fig1:Effect of E.operculata leave extracts on DPPH assay. Fig A,B,C determine the correlation between \%inhibition and concentration of extracts and ascorbic.Fig D shows DPPH scavenging activity.
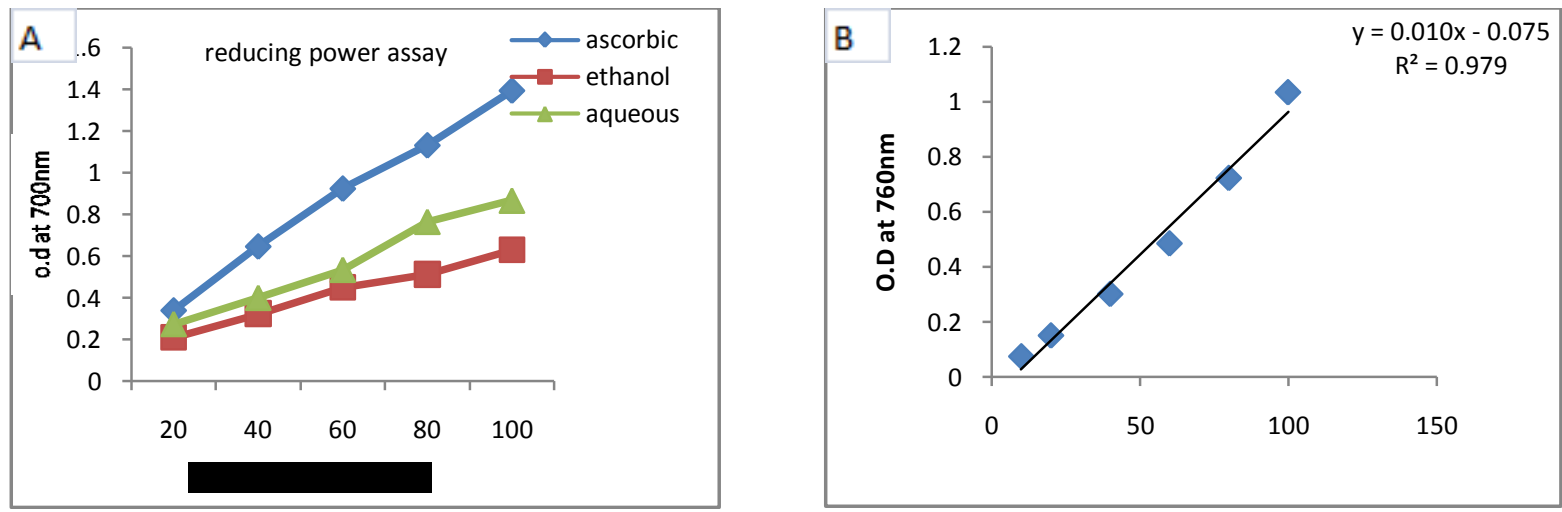

Fig2: A. Reducing ability of the standard ascorbic acid and the extracts at various concentrations. B.Total phenolic content(mg/gm GAE).

\section{References:}

[1]. Tiwari, Antioxidant: new generation therapeutic base for treatment of polygenic disorders, Current science 86, $2004,8$.

[2]. Noguchi N, Watanabe A, Shi H, Diverse functions of antioxidants,Free Radic. Res, 33, 2000, 809-817.

[3]. Tiwari AK, Imbalance in antioxidant defense and human disease: multiple approach of natural antioxidants therapy, Curr S, 2001, $81,1179-1187$.

[4]. Loi DT, Vietnamese medicinal plants and herbs. Hanoi Pub. House Techno.Vietnam, 1986, 437-438.

[5]. Anthony YHW, Mary MYW, Kwan HS, Melanie CYC, Chaua CF, Christopher HKC, Inhibition of ATPases by Cleistocalyx operculatus. Apossible mechanism for the cardio tonic actions of the herb. Vasc. Pharm, 2002, 38,163-168.

[6]. Brain KR, Turner TD. Practical evaluation of phytopharmaceuticals. 1st edition. Wright-Scientechnica, Bristol; 1975,144.

[7]. Evans WC, Trease, Evans. Pharmacognosy, 14th Edition, Bailiere Tindall W.B. Sauders company ltd, London; 1996, 224 - 228,293 $-309,542-575$.

[8]. Wong CK, Ooi VEC, Ang PO. Chemosphere, 2000, 41, 173-176.

[9]. Skerget M, Kotnik P, Hadolin M, Hras A, Simonic M, Knez Z, Phenols,proanthocyanidines, flavones and flavonols in some plant materials and their antioxidant activities, Food chem. 2005, 89,191-198.

[10]. Ferreira ICFR, Baptista M, Vilas-Boas, Baros L, Free radical scavenging capacity and reducing power of wild edible mushrooms from northeast Portugal: individual cap and stipe activity. Food chem. 2007, 100, 1511-1516.

[11]. Huang D, Ou B, Prior RL, The chemistry behind antioxidant capacity assays, Agriculture food Chem. 2005, 53, 1841-1856. 
[12]. Karagozler AA, Erdag B, Emek YC, Uygun DA, Antioxidant activity and proline content of leaf extracts from Dorystoechas hastate. Food Chem. 2008, 111, 400-407.

[13]. Oktay M, Gulcin I, Kufrevioglu OI. Determination of invitro antioxidant activity of fennel (Foeniculum vulgare) seed extracts. Lebensum.Wiss.U.Technol 2003; 36:263-271.

[14]. Pan Y, Wang K, Huang S, et al. Antioxidant activity of microwave-assisted extract of longan (Dimocarpus longan Lour.) peel, Food Chem, 2008, 106-264. 